\title{
Kefir and champagne vinegar to defeat bacterial vaginosis in woman, avoiding oral metronidazole, clindamycin and bothersome douchings
}

\section{Piotr Brzezinski ${ }^{1,2}$, Lorenzo Martini ${ }^{3}$}

${ }^{1}$ Institute of Biology and Environmental Protection, Pomeranian Academy, ul. Arciszewskiego 22A, 76-200 Slupsk, Poland, ${ }^{2}$ Department of Dermatology, $6^{\text {th }}$ Military Support Unit, Ustka, Poland, ${ }^{3}$ Department of Pharmaceutical Biotechmologies, University of Siena, Siena, Italy

Corresponding author: Lorenzo Martini, E-mail: martinil163@libero.it

\begin{abstract}
Scope ouf our study is to treat with natural remedies vaginitis in woman, when it has been detected the disease originates from bacterical assault (Gardnerella vaginalis and/or Streptococca spp.) in order to avoid the administration of perilous antibiotics and elicit sexual desire and eliminate pain during urination in the woman who has suffered from this disease after 4-5 days only. We have to proceed with the preliminary phase of a simplest test (the ammin whiff test) and determine the type of vaginitis and thus treat it using champagne or cider vinegar to adjust mucosal $\mathrm{pH}$ and kefir, a fermented beverage, that is extremely rich in mesophyllic bacteria, apt to reveal an important and suggestive function regard vaginal microbes.
\end{abstract}

Key words: Vaginitis; Vulva; Kefir; Gardnerella vaginalis; Champagne vinegar

\section{INTRODUCTION}

Vaginitis is an inflammation of the vagina and possible vulva It can result in discharge, itching and pain, and is often associated with an irritation or infection of the vulva. Infected women may also be asymptomatic.

It is usually due to infection. The three main kinds of vaginitis are bacterial vaginosis (BV), vaginal candidiasis, and trichomoniasis. A woman may have a combination of vaginal infections at one time.

Bacterial vaginosis is generally sustained by gardnerella vaginalis and it is preferable to individuate if the woman who suffers from vaginitis, has this infection instead of fungal assaults, in order to treat the disease by the best and more rapid way and to avoid to administer to her antimycotics instead of antibiotics and vice versa and moreover, to trace the best path to cure the malaise owing to natural medicaments.
Gardnerella is treated commonly by metronidazole [1] clindamycin [2-4].

Now it is well acquainted that amongst the manifold side effects given by metronidazole, the most common are numbered in Box 1.

And amongst the side effects given by assumption of clindamycin, these are the most severe (Box 2).

A recent paper [5] asserts that in case of aggression of gardnerella or other microbiota typical of vaginosis, the physiological production of lactic acid and other short chain fatty acids, apt to mantain $\mathrm{pH} 4,5$ (optimal for combating the occurrence of yeasts or bacterial infections in vagina and vulva), decreases abruptely or goes to end.

These bacteria are able, indded, to produce long chain fatty acids, as acetates, propionates, butyrates, and succinates.

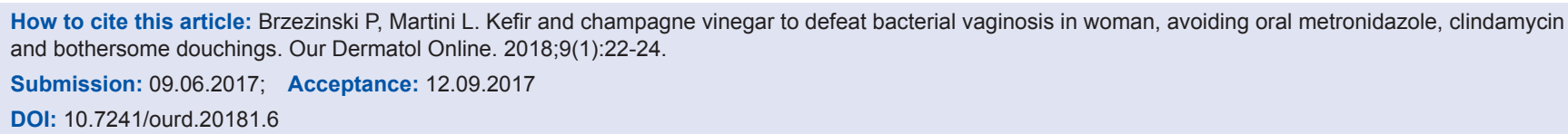


Box 1: The side effects by metronidazole

numbness or tingling in hands or feet;

white patches or sores inside mouth or on lips;

pain or burning when urinating;

diarrhea that is watery or bloody;

vision problems, pain behind eyes:

trouble concentrating, slurred speech, mood or behavior changes, tremors,

muscle twitching, seizure (convulsions);

fever, chills, muscle pain, confusion, headache, sore throat, neck stiffness, increased sensitivity to light, drowsiness, nausea and vomiting; or severe skin reaction -- fever, sore throat, swelling in your face or tongue, burning in eyes, skin pain, followed by a red or purple skin rash that spreads (especially in the face or upper body) and causes blistering and peeling.

Box 2: The side effects by clindamycin

\begin{tabular}{ll}
\hline $\begin{array}{l}\text { abdominal or stomach cramps, pain, or } \\
\text { tenderness }\end{array}$ & $\begin{array}{l}\text { heartburn } \\
\text { loss of appetite } \\
\text { bleeding gums }\end{array}$ \\
$\begin{array}{l}\text { plistering, peeling, or loosening of the skin sexual intercourse } \\
\text { painful or difficult urination }\end{array}$ \\
$\begin{array}{l}\text { blood in the urine or stools } \\
\text { blurred vision }\end{array}$ & $\begin{array}{l}\text { pinpoint red spots on the skin } \\
\text { redness of the skin }\end{array}$ \\
chest pain & shortness of breath \\
cough or hoarseness & sore throat \\
dark urine & sores, ulcers, or white spots \\
decrease in the amount of urine & in the mouth or on the lips \\
diarrhea & swollen glands \\
dry mouth & thick, white vaginal discharge \\
fast heartbeat & with no odor or with a mild \\
fever with or without chills & odor \\
general feeling of tiredness or weakness & unpleasant breath odor \\
headache & bleeding or bruising \\
& unusual weight loss \\
& yellow eyes or skin. \\
\hline
\end{tabular}

A simplest method to distinguish if the vaginitis is originated by bacterial aggressions or fungal assaults is the ammin whiff test, that is used to determine the quantity of gardnerella vaginalis in order to adjust the dosage of antibiotics, and in the preliminary phase, during the preparation of the kit, and using a $10 \% \mathrm{KOH}$ solution, a strong fragrance of fish comes out and this is the indisputable sign of presence of these bacteria and/ or Streptococca spp and the presence or co-presence of fungi or Trichomoniasis is exorcised at all.

Other discovered too that mesophyllic bacteria are able to oxidate octanoates at temperatures comprised between $7.5^{\circ} \mathrm{C}$ and $40^{\circ} \mathrm{C}$, this fact signifies that mesophyllic bacteria are capable to denature vaginal commensal bacteria [6].

Kefir is a fermented milk drink that originated in the north Caucasus Mountains made with kefir "grains", a yeast/bacterial fermentation starter.It is prepared by inoculating cow, goat, or sheep milk with kefir grains [7] and moreover these grains called kefiran contain bacterial colonies especially mesophyllic living symbiotically with yeasts.

An acidic milieu (below 4.5) must be reached and naturally speaking the best way is to cleanse vagina with douche containing pure cider vinegar, or to insert a cotton ball soaked in cider or champagne vinegar and let it stay all through the night inside vagina.

Kefir must be spread as a liquid emulsion every time the woman has urinated and washed with lukewarm water and savon de marseille (that shows a mild antibacterial function too).

Kefir must be kept in fridge, for this, the woman had to keep the beverage in fidge at home (or even at work).

Applications were 6-7 pro day.

\section{MATERIALS AND METHODS}

We have recruited a woman (27 y. old) who had declared to feel a severe annoyance during urinating, perpetual itching during day and night in her vagina and vulva.

She was very embarassed when she was at work or spent her time in social occasions.

She was sure not to suffer or have suffered from Candida albicans since the Candida anti-body blood test was negative, she has always avoided high sugar diet, never taken antibiotics, did not suffer from chronic stress, did not assume contraceptive pill, and did not have diabetes.

She used to wear banana hammock, even she used to wash it almost three times pro week. She has thought she had mistaken the usage of the detergent for washing her intime underwear.

First of all, we have effectuated the ammine whiff test (only the preliminary phase) and we assayed the penetrating fish odour pouring a $\mathrm{KOH} 10 \%$ solution directly in her discharge, but we identified by electronic microscope even the presence of Gardnerella and Streptococca spp.

We began the experimentations following this schedule:

the volunteer had to insert a cotton ball (as it were a normal vaginal swab) all the night long for five nights, almost 7-8 hours.

During the day, she had to spread kefir (kept in cool) every time she had urinated. 
Table 1: Responses of ammin whiff tests effectuated every day for five days

\begin{tabular}{lc}
\hline Number of day of treatment & Response to whiff test \\
\hline 1 & + \\
2 & + \\
3 & - \\
4 & - \\
5 & - \\
\hline
\end{tabular}

+ stands for positive, and thus positive reaction to ammin whiff test, - stands for negative, idest no malodour comes out from whiff test

Table 2: Sensation of itching during the treatment of five days.

\begin{tabular}{ll}
\hline Number of day of treatment & $\begin{array}{l}\text { Feeling of itching referred from } \\
\text { the volunteer }\end{array}$ \\
\hline 1 & a \\
2 & b \\
3 & d \\
4 & $\mathrm{e}$ \\
5 & $\mathrm{e}$ \\
\hline a) Itching during day and night; b) Itching only during the day; c) Itching only \\
$\begin{array}{l}\text { after urinated; d) Mild itching through all the day, but tolerable; e) Absence } \\
\text { of itching }\end{array}$
\end{tabular}

\section{RESULTS}

From Table 1 it is possible to observe that after the second day discharge and unpleasant odour (simply adding $\mathrm{KOH}$ solution to her urine at the mornig) disappeared at all.

From Table 2 it is possible to behold the feeling of itching, according to a conventional scale:

a) Itching during day and night

b) Itching only during the day

c) Itching only after urinated

d) Mild itching through all the day, but tolerable

e) Absence of itching

\section{DISCUSSIONS AND CONCLUSIONS}

It is suggestive to herald that avoiding drastic antibiotics, endowed of side effects too often risky, is possible to treat bacterial vaginosis (when the co-presence or co-presence of fungi are exorcised), a woman suffering from bacterial vaginosis, who declares pain in urinating, lack of sexual desire, extreme itching and malodorous abrupt discharges, may be treated by simplest natural remedies as champagne or cider vinegar (to be applied as a swab during the night) and spreading kefir 6-7-8 times pro day.

\section{REFERENCES}

1. Jones BM, Geary I, Alawattegama AB, Kinghorn GR, Duerden BI. In-vitro and in-vivo activity of metronidazole against Gardnerella vaginalis, Bacteroides spp. and Mobiluncus spp. in bacterial vaginosis. J Antimicrob Chemother. 1985;16:189-91.

2. Kiser CJ, Urish KL, Boateng HA. Development of Clostridium septicum gas gangrene as an adverse effect of clindamycin-induced Clostridium difficile infection in a pediatric patient. J Pediatr Orthop. 2014;34:e19-21.

3. Khan FZ. Microbial Infections in females of childbearing age and therapeutic interventions. Rawal Med J. 2011;36:178-81.

4. Ferris DG, Litaker MS, Woodward L, Mathis D, Hendrich J. Treatment of bacterial vaginosis: a comparison of oral metronidazole, metronidazole vaginal gel, and clindamycin vaginal cream. J Fam Pract. 1995;41:443-9.

5. Aldunate M, Srbinovski D, Hearps AC, Latham CF, Ramsland PA, Gugasyan R, et al. Antimicrobial and immune modulatory effects of lactic acid and short chain fatty acids produced by vaginal microbiota associated with eubiosis and bacterial vaginosis. Front Physiol. 2015;6:164.

6. Sultzer BM. Oxidative activity of psychrophilic and mesophyllic bacteria on saturated fatty acid. J Bacteriol. 1961;82:492-7.

7. Altay F, Karbancioglu-Güler F, Daskaya-Dikmen C, Heperkan D. A review on traditional Turkish fermented non-alcoholic beverages microbiota, fermentation process and quality characteristics. Int J Food Microbiol. 2013;167:44-56.

Copyright by Piotr Brzezinski, et al. This is an open-access article distributed under the terms of the Creative Commons Attribution License, which permits unrestricted use, distribution, and reproduction in any medium, provided the original author and source are credited.

Source of Support: Nil, Conflict of Interest: None declared. 